\title{
Vaktaalrubriek
}

\section{Ontwikkeling van 'n Afrikaanse vaktaal vir die Oseanologie}

\author{
J.R.E. Lutjeharms, Nasionale Navorsingsinstituut vir Oseanologie, W.N.N.R., Posbus 320, Stellenbosch 7600
}

Die skepping en voortdurende byhou van 'n geskikte, bruikbare en lewendige Afrikaanse vaktaal is op die meeste vakgebiede 'n gedugte taak. Hiervan getuig etlike onlangse bydraes tot die vaktaalrubriek van die Tydskrif vir Natuurwetenskap en Tegnologie. ${ }^{1,2}$ Die wye bekendstelling van die geskepte vakterme en die aanmoediging vir die gebruik daarvan is 'n taak waarvan die omvang waarskynlik nie veel kleiner is nie. ${ }^{3}$ Daar bestaan egter nog steeds vakgebiede waarop selfs die eerste wankele skredes tot die skepping van 'n behoorlik Afrikaanse vaktaal gegee moet word. Tot op groot hoogte is Oseanologie so 'n vakgebied. Hiervoor is daar belangrike historiese redes.

\section{Huidige stand van Afrikaans}

Die mariene wetenskappe, of Oseanologie, het in Suid-Afrika 'n lang en mooi Engelse tradisie. Aan die begin van die twintigste eeu het dr. J.D.F. Gilchrist, 'n jong Britste mariene bioloog, die fondament vir die mariene wetenskappe in Suid-Afrika gelê toe hy beide as staatsbioloog sowel as hoogleraar in Dierkunde aan die Universiteit van Kaapstad gewerk het. As hoof van die staat se visserynavorsing is hy opgevolg deur studente wat onder hom by U.K. studeer het.

'n Toenemende belangstelling in die Mariene Fisika, Skeikunde en Geologie aan hierdie universiteit het daartoe gelei dat daar in die sestigerjare 'n oorkoepelende Instituut vir Oseanografie aan die U.K. gestig is en dat ' $n$ leerstoel in die Oseanografie in 1959 hier gevestig is.

Tot redelik onlangs het alle studente in die Oseanologie dus afgestudeer aan universiteite waar Engels die voertaal is. Dit was dan ook sowat die enigste voedingsbron van navorsingspersoneel vir bestaande navorsingsinstitute soos die S.A. Museum, die Navorsingsinstituut vir Seevisserye, die Oseanografiese Navorsingsinstituut in Durban en die $\mathrm{Na}$ sionale Navorsingsinstituut vir Oseanologie van die W.N.N.R. op Stellenbosch. Die (eentalige) South African Directory of Marine Scientists, Technologists and Technicians ${ }^{4}$ gee 153 persone aan wat in 1969 in Suid-Afrika as oseanoloë beskou kon word, waarvan alleen 36 , dus $24 \%$, Afrikaanstalig was. Publikasies, navorsingsverslae en simposiumverhan- delinge was gedurende hierdie jare om verstaanbare redes oorwegend Engelseentalig. Die stand en gebruik van Afrikaans in die Oseanologie is op die oomblik gevolglik swak. 'n Paar voorbeelde kan dien om hierdie stelling te staaf. Die publikasies van die Nasionale Navorsingsinstituut vir Oseanologie van die W.N.N.R. dek die volle interdissiplinêre omvang van die Oseanologie en is waarskynlik goed verteenwoordigend van sowel die publikasietempo as die aard en taalgebruik van publikasies deur die SuidAfrikaanse oseanologiese navorsingsgemeenskap in sy geheel. Die taalmedium in die W.N.N.R. is hoofsaaklik die keuse van die skrywer self. Uit Tabel I, hieronder, ontleen aan die Instituut se jaarverslae, blyk dit dat daar 'n jammerlike gebrek aan Afrikaanse publikasies is.

TABEL I

Taalgebruik in publikasies van die Nasionale Navorsingsinstituut vir Oseanologie.

\begin{tabular}{|c|c|c|c|c|}
\hline Jaar & Verslae & Artikels & $\begin{array}{c}\text { Persen- } \\
\text { tasie in } \\
\text { Afri- } \\
\text { kaans }\end{array}$ & $\begin{array}{c}\text { Beraamde per- } \\
\text { sentasie navor- } \\
\text { singspersoneel } \\
\text { Afrikaanstalig }\end{array}$ \\
\hline 1975 & 24 & 14 & 3 & 39 \\
1976 & 32 & 26 & 0 & 46 \\
1977 & 16 & 9 & 0 & 50 \\
1978 & 40 & 14 & 0 & 46 \\
1979 & 61 & 26 & 2 & 53 \\
1980 & 98 & 37 & 2 & 55 \\
1981 & 110 & 35 & 5 & 52 \\
\hline Totaal & 381 & 161 & $2,4 \%$ & $49 \%$ \\
\hline
\end{tabular}

Ongeveer $60 \%$ van hierdie publikasies is kontraken navorsingsverslae van hoofsaaklik plaaslike belang.

Die gebruik van Afrikaans by kongresse, simposia en ander saamtrekke hier te lande toon 'n soortgelyke patroon. 'n Ontleding van die taalgebruik by die driejaarlikse Nasionale Oseanografiese Simposia, soos verkry uit die gepubliseerde voordragsamevattings, word in Tabel II hieronder uiteengesit. 
TABEL II

Taalgebruik by Nasionale Oseanografiese Simposia in Suid-Afrika.

\begin{tabular}{|c|c|c|c|}
\hline Jaar & $\begin{array}{c}\text { Aantal } \\
\text { bydraes }\end{array}$ & $\begin{array}{c}\text { Persentasie } \\
\text { in } \\
\text { Afrikaans }\end{array}$ & $\begin{array}{c}\text { Beraamde } \\
\text { persentasie } \\
\text { Afrikaanse } \\
\text { geregistreerdes }\end{array}$ \\
\hline 1970 & 31 & 0 & 18 \\
1973 & 51 & $(0)$ & 32 \\
1976 & 53 & 3 & 25 \\
1979 & 126 & $(0)$ & 17 \\
1983 & 189 & 4 & 17 \\
\hline
\end{tabular}

'n Ontleding van die registrasiepatroon van deelnemers aan die jongste simposium van hierdis aard, wat in Januarie 1983 op Grahamstad gehou ., is insiggewend. Van die totaal van 209 afgevaardigdes was 9 van oorsee. Van die 200 Suid-Afrikaanse afgevaardigdes was 35 , dus $18 \%$, Afrikaanstalig, maar van hierdie 35 het net 9 in Afrikaans geregistreer. Vakkundige bydraes tot die verrigtinge self toon 'n ooreenkomstige patroon. Die redes vir hierdie afkeer aan hul eie taal onder Afrikaanssprekende oseanoloë is waarskynlik drieërlei: sterk druk om die enkele buitelandse besoekers tegemoet te kom deur alleen Engels te praat, 'n valse gevoel van wellewendheid by Afrikaanssprekendes teenoor Engelssprekende kollegas en laastens, weens die lang Engelse tradisie, 'n onbekendheid en onbeholpenheid met die Afrikaanse terminologie.

Brink $^{5}$ wys daarop dat met die wêreldwye aanvaarding van Engels as internationale kongres-, publikasie- en kommunikasietaal in die natuurwetenskappe en in die tegnologie Afrikaans byna niks slegter daaraan toe is as selfs ou erkende publikasietale soos Duits, Nederlands of selfs Frans nie. Hierdie tale wedywer egter tot op groot hoogte slegs in die internasionale arena met Engels, terwyl hulle op eie werf sterk staan waar dit by publikasies van meer plaaslike belang kom en ook waar dit binnelandse vergaderings, notules, memoranda, inligtingstukke, kontrakverslae, briewe en so meer raak.

Dit is met Afrikaans egter nie die geval nie. Die feit dat die Afrikaanse navorser, om internasionale erkenning onthalwe, in Engels publiseer, kan baie maklik, om redes hierbo genoem, die newe-effek verkry dat hy hom ook plaaslik van Engels begin bedien. In die Oseanologie in Suid-Afrika is dit inderdaad verontrustend om waar te neem dat hierdie neweeffek selfs daartoe aanleiding gee dat korrespondensie oor vakaangeleenthede tussen Afrikaanstaliges soms in Engels plaasvind. Die ernstige taalverskuiwing wat uit tabelle I en II hierbo blyk, is waarskynlik ook simptomaties van hierdie tendens.

\section{Behoefte aan 'n Afrikaanse vaktaal}

Die vraag ontstaan dus onmiddellik of daar op die oomblik binne hierdie vakgebied hoegenaamd ' $n$ behoefte aan 'n Afrikaanse vaktaal bestaan. Die ant- woord daarop is beslis bevestigend. In die eerste plek is dit ' $n$ effektiewe eerste stap om die bose kringloop van ons-skrywe-Engels-weens-die-gebrek-aan-Afrikaanse-terminologie $\rightarrow$ daar-bestaan-geen-Afrikaanse-terminologie-nie-omdat-alles-in-Engels-is te deurbreek. Verder is daar nietemin 'n beduidende aantal publikasies, briewe, notules, memoranda, en so meer, van instansies binne die staatsdiens, van universiteite en van statutêre liggame wat oor oseanologiese aangeleenthede handel en wat in Afrikaans opgestel word. Onlangse ontwikkelings op die gebied van die tersiêre onderwys het ook geleenthede en behoeftes in dié verband geskep. So word daar byvoorbeeld die afgelope paar jaar aan die Departement Dierkunde van die Universiteit van Port Elizabeth mariene wetenskappe aan studente uit albei taalgemeenskappe gedoseer. Ook hier het daar dus 'n onmiddellike behoefte aan ' $n$ meer toereikende vaktaal ontstaan. Die totstandkoming van die Navorsingsgroep Oseaaningenieurswese aan die Universiteit van Stellenbosch het hierdie behoefte versterk.

Hierdie behoefte is dan ook alreeds in etlike verwante vakgebiede ondervang. Die Fisikawoordeboek $k^{6}$ van die Vaktaalburo bevat fisies-oseanologiese terme, die Dierkundewoordeboek $k^{7}$ terme oor mariene k' 'ogie, terwyl die Tak Geologiese Opname van die Departement Mynwese 'n tweetalige lys geologiese en verwante terme ${ }^{8}$ die lig laat sien het wat ook die mariene veld aansny. Die Vloottaalburo van die Suid-Afrikaanse Vloot het verskeie woordelyste oor vlootaangeleenthede die lig laat $\operatorname{sien}^{9-12}$ en so 'n bruikbare seemanstaal geskep wat vir die praktiese oseanoloog op see van groot waarde is. Die tegniese woordeboek van Terblanche, ${ }^{13}$ wat sy oorsprong in die daaglikse praktyk gehad het, ${ }^{14}$ is in hierdie verband ook van veel nut. Uit die geledere van die kusingenieurs het die behoefte aan 'n Afrikaanse vakterminologie so sterk na vore getree dat 'n vaste subkomitee van die Suid-Afrikaanse Nasionale Komitee vir Seehulpbronne (SANECOR) gevorm is om 'n verklarende woordelys van Afrikaanse kus- en haweingenieursterme op te stel. Daar word op die oomblik nog aan hierdie opdrag gewerk.

Op die vakgebied Oseanologie vind al hierdie onderskeie dissiplines raakpunte. Die gevaar bestaan dus onmiddellik dat waar oseanoloë hulle Afrikaanse terminologie uit hierdie uiteenlopende bronne kan gaan haal, daar 'n element van taalverwildering mag intree of dat daar, soos D.F. du Toit Malherbe dit alreeds in 1918 gestel het ${ }^{15}$, 'n "erbarmelike brabbeltaal in die laboratorium en elders" mag ontstaan.

\section{Ontwikkeling van 'n aanvaarbare vaktaal}

Die feit dat die Oseanologie oorvleuel met soveel ander vakgebiede hou vir die skepping van 'n behoorlike vaktaal sowel voordele as nadele in. Aan die positiewe kant is daar die feit dat vaktaalkenners in aanverwante vakke al heelwat werk gedoen het wat in die oseanologiese vaktaal bruikbaar is, en sonder aarseling daarin opgeneem kan word. Aan die Navorsingsinstituut vir Seevisserye word daar byvoor- 
beeld al vir baie jare op die terrein van visserynavorsing vertaalwerk gedoen en 'n groot bron van parate kennis is hier beskikbaar.

Aan die negatiewe kant is daar die probleem dat verskillende instansies verskillende woorde mag skep vir die weergee van 'n bepaalde begrip. So, byvoorbeeld, is die uitdrukking dead reckoning (die bepaling van 'n skip se posisie ter see, deur berekening van die koerse wat gevolg en die afstand wat afgelê is) ${ }^{16}$ deur een instansie vertaal met gisbestek. 'n Ander groep het dit egter vertaal met kritieke berekening. Soms gebeur dit dat woordskeppers erg verknog raak aan hul eie skeppings en nie bereid is om sulke maaksels prys te gee ten bate van eenvormigheid nie en daar ontstaan dan so allerlei institusionele subtaaltjies met gepaardgaande taalverwarring.

Nietenmin kom daar uit sekere oorde pragtige woordskeppings; kragtige, bruikbare en vir die Afrikaanse oor aanvaarbare oseanologiese vakterme. Naudé17 toon met 'n paar voorbeelde aan hoe etlike geskepte Afrikaanse fisikaterme meer verfynde en wetenskaplik meer korrekte terme is en as die soms eienaardige Engelse woorde van Amerikaanse oorsprong. Sulke vondste is daar ook in die Oseanologie. So byvoorbeeld is manganese nodules, die kluiterige afsettings van mangaan en yster op die seebodem, vertaal met die klinkende term mangaanknolle. Materiaal wat op die seebodem geplaas word om die beweging van bodemsediment te volg, in Engels tracer, word spoorsand geneem. Die term vir die garnaalsoort wat in simbiotiese verwantskap saam met sekere vissoorte lewe deur van hul uitwendige parasiete te vreet, die cleaner prawn, is vertaal met diensgarnaal. Posthumus ${ }^{18}$ het al aangetoon dat, nieteenstaande die skepping van 'n horde papierkindertjies wat nooit verder as die bladsye van die woordelyste beweeg nie, 'n groot aantal nuttige en diensbare vaktaalskeppings besig is om Afrikaans te verryk. Die feit dat die Afrikaanse vaktaal 'n dubbelle stel bronne het waaraan hy sy terminologie kan ontleen, skep 'n unieke geleentheid tot fyner betekenisskakering en betekenisdifferensiasie. Terblanche $^{13}$ wys tereg daarop dat terwyl die Germaanse term vir die Afrikaanse beginner dadelik verstaanbaar is, die Grieks-Latynse term 'n voordelige skakel met die internasionale vakliteratuur vorm. Die moontlikheid bestaan dat ' $n$ geringe verskil in betekenis aan die woorde van verskillende oorsprong geheg kan word, waardeur die vaktaal veel fyner genuanseerd sal raak. Hierdie potensiële ryk bron lê nog totaal onderbenut, veral in die Oseanologie.

In sy boek oor die ontstaan en oorlewing van die Afrikaanse taal ${ }^{19}$ haal Steyn 'n Nederlandse skrywer aan: "Het Algemeen Beschaafd (Nederlands) dat de Belgen schrijven bezit een eigenschap die alle anderen overheerst: hun Nederlands is veel gemakkelijker in het Frans te vertalen als het onze." 20

Die gevaar wat hier vir Vlaams uitgelig word, naamlik dat dit 'n verhollandste Frans sal word wat sy eie taalkarakter en egtheid verloor, bestaan ook vir Afrikaans en veral vir sy vaktaal. Een van die mees voor-die-hand-liggende slaggate in hierdie verband is die neiging om enkelwoorde in Engels te alle tye met ander enkelwoorde te wil vertaal, terwyl die meer omskrywende Afrikaanse sinsnede veelal die begrip beter omvat en soms vir minder misverstand vatbaar is.

\section{'n Praktiese woordelys}

Vir die vertaler, vir die tweetalige oseanoloog en selfs vir die sekretaresse wat die verloop van 'n vergadering oor oseaan-aangeleenthede moet vertaal, is daar op die oomblik geen eenmalige bron waarin die Afrikaanse term met 'n groot mate van waarskynlikheid te vinde sal wees nie. Terwyl die Oseanologie soveel vakgebiede omsluit, is dit 'n onbegonne taak vir die gemiddelde persoon om ' $n$ bepaalde woorde in die groot versameling aanverwante vakwoordelyste uit te snuffel. Waar die woord alleen binne die Oseanologie tuishoort, bestaan daar verder die besliste moontlikheid dat die Afrikaanse term glad nie bestaan nie. Dit is dus duidelik dat daar 'n behoefte aan 'n praktiese Afrikaanse woordelys vir die Oseanologie bestaan.

Ek en ' $n$ paar kollegas is die afgelope paar jaar besig om so ' $n$ voorlopige tweetalige woordelys saam te stel. Die werkwyse was min of meer as volg. Eerstens is al die bestaande woordelyste wat kollegas vir eie gebruik opgestel het, byeengebring en gekonsolideer. In die tweede plek word 'n uitgebreide versameling vakterme in Engels byeengebring. Hiervoor word gebruik gemaak van bestaande woordelyste, glossariums, indekse by handboeke, vakpublikasies en so meer.

Vakterme word ook aangeteken tydens kongresse, simposia en vergaderings. So is daar, terloops, vasgestel in watter merkwaardige mate die woordeskat van die gesproke van dié van die geskrewe vaktaal verskil. Dit mag wees dat hier sprake is van 'n vertraging in die inburgering van terminologie deurdat die gesproke vaktaal eers 'n sekere onomskrewe status moet bereik voordat dit as skryftaal aanvaarbaar word.

Met verloop van tyd word die Afrikaanse ekwivalente vir al hierdie woorde opgediep, waar nodig keuses tussen verskillende moontlikhede gemaak of nuwe woorde geskep, en die voorlopige lys terme dan verder georden.

In hierdie proses duik daar voortdurend praktiese probleme op, sommige deel van die saamstel van enige woordelys, ander uniek aan die saamstel van'n woordelys in Oseanologie. Een van die probleme uniek aan die Oseanologie raak die grense van die vakgebied. Soos alreeds aangetoon, oorvleuel die Oseanologie met die mariene komponente van die Geologie, Fisika, Skeikunde, Biologie en Ingenieurswese. Waar 'n term uit hierdie dissiplines dus alleen gebruik word binne die oseaan-georiënteerde deel van die betrokke vakgebied, hoort dit kennelik tuis in 'n oseanologiese woordelys.

Waar vakterme binne elke betrokke dissipline meer algemeen gebruik word, dit wil sê beide in die oseaangeoriënteerde deel en elders, kan die gemiddelde 
oseanoloog tog nog steeds verwag om die woord in 'n praktiese oseanologiese woordelys te vind. Om 'n verstandige balans te vind tussen die bevrediging van hierdie verwagting en die praktiese beperkings op die omvang van 'n woordelys, skep voortdurende besluitnemingsprobleme.

Die praktiserende oseanoloog kom ook daagliks in aanraking met terme uit die Weerkunde, Geografie, Hidrografie, Skeepvaartkunde, Kartografie en die visserywetenskappe. Waar hierdie terme sy eie bedrywighede direk raak, word hulle deel van sy eie woordeskat en sal 'n praktiese woordelys ook tot op sekere hoogte hierdie woorde moet insluit.

'n Belangrike komponent van die Oseanologie, naamlik die Oseanografie, is 'n kleinboet van die Geografie en is hoofsaaklik beskrywend van aard. Om dié beskrywende Oseanografie te bedien, is dit dus belangrik dat 'n woordelys ook aan die Afrikaanse ekwivalente van sekere oseaanplekname ruimte sal gee. Weer eens moet daar dan geoordeel word oor die toepaslikheid van 'n sekere pleknaam binne die Suid-Afrikaanse belangeveld. Plekname soos die Arktiese Oseaan (Arctic Ocean) vind wel 'n plek vanweë hul algemene belang, die Cobbseeberg (Cobb Seamount) vanweë bekende fisiese verskynsels wat hier vir die eerste keer beskrywe is en nou redelik onlosmaaklik met hierdie seeberg verbind bly, en laastens natuurlik ook onontbeerlike plaaslike plekname soos die Agulhasbank (Agulhas Bank), Walvisrif (Walvis Ridge) en dies meer. Sommige van hierdie plekname se Afrikaanse weergawes kan so voor-die-hand-liggend lyk dat daar twyfel bestaan oor die noodsaaklikheid om dit in 'n vakwoordelys op te neem. Die praktiese ervaring het egter getoon dat sonder 'n algemeen aanvaarde rigsnoer daar 'n verskeidenheid spellings en weergawes selfs vir hierdie terme onstaan.

Die voorneme is vir eers dat hierdie woordelys na voltooiing wyd onder belangstellendes gesirkuleer sal word vir kommentaar, kritiek en verdere bydraes. Indien daar genoegsame belangstelling bestaan, sou so 'n voorlopige woordelys kan dien as die vertrekpunt vir 'n meer amptelike woordelys, miskien deur die regte instansies. Verder is daar die verwagting dat dit as basis kan dien vir 'n tweetalige verklarende glossarium van oseaanterme, asook vir'n bydrae van vakterme tot die Woordeboek van die Afrikaanse Taal. ${ }^{21}$ Enige bydraes of kommentaar met betrekking tot die woordelys word nou alreeds met groot dankbaarheid ontvang.

\section{Dankbetuigings}

Ek bedank graag professore T.E. Erasmus en D. Baird van die Universiteit van Port Elizabeth; mnr. A.A.L. Beneke, mev. A.C. Steyn en mnr. H.J. Chamberlain van die Nasionale Navorsingsinstituut vir Oseanologie; mnr. H. Boonstra en mej. S.A. du Toit van die Navorsingsinstituut vir Seevisserye, mnr. F. Kapp van die firma Geustyn, Forsyth en Joubert Ing. en kommandeur D.F. Louw van die Vloottaalburo vir hulle waardevolle bydraes en aanmoediging.
Hierdie artikel is in die skrywer se privaat hoedanigheid opgestel en oortuigings hierin uitgespreek weerspieël nie noodwendig die sienswyse van die W.N.N.R. nie.

\section{Verwysings}

1. Nelson, H.D. (1982). Afrikaanse terminologie-probleme van en 'n uitdaging vir die analitiese chemikus, S. Afr. Tydskr. Natuurwet. Tegn., 1, 112-113.

2. (Anoniem). (1982). Hersiening van die statistiekwoordeboek, S. Afr. Tydskr. Natuurwet. Tegn., 1, 59.

3. Pieterse, M.J. (1982). Waarom sou die chemikus in Afrikaans publiseer?, S. Afr. Tydskr. Natuurwet. Tegn., 1, 10-15.

4. South African Oseanographic Data Centre. (1969). A South African directory of marine scientists, technologists and technicians, The South African National Committee for Oseanographic Research, 16 pp.

5. Brink, C.v.d.M. (1975). Waarom sou wetenskaplikes in Afrikaans publiseer? In Afrikaans: dit is ons erns, Suid-Afrikaanse Akademie vir Wetenskap en Kuns, Pretoria, 61: 13-28.

6. Vaktaalburo. (1977). Fisikawoordeboek. Vaktaalburo van die Suid-Afrikaanse Akademie vir Wetenskap en Kuns, Butterworth, Durban, 355 pp.

7. Vaktaalburo. (1982). Dierkundewoordeboek. Die Vaktaalburo, Departement van Nasionale Opvoeding, Die Staatsdrukker, Pretoria, 147 pp.

8. Geologiese Opname. (1970). Tweetalige lys geologiese en verwante terme. Afdeling Geologiese Opname, Departement Mynwese, Die Staatsdrukker, Pretoria, 154 pp.

9. Vloottaalkantoor. (1969). Voorlopige duikbootwoordelys. Engels-Afrikaans-Frans. Vloottaalkantoor, Suid-Afrikaanse Vloot, $98 \mathrm{pp}$.

10. Vloottaalburo. (1970)). Duikbootjag-, torpedo- en duikterme. Engels-Afrikaans. Vloottaalburo, Suid-Afrikaanse Vloot, $108 \mathrm{pp}$.

11. Taaldiens Suid-Afrikaanse Weermag. (1974). Seemansterme vir die seilsport. Engels-Afrikaans. Taaldiens, S.A. Weermag, Die Vloot se Drukpers, 194 pp.

12. Vloottaalburo. (1979). Mynveewoordelys. Vloottaalburo, Direktoraat Taaldiens, S.A. Weermag, Simonstad, 64 pp.

13. Terblanche, H.J. (1976). Engels-Afrikaanse Tegniese Woordeboek. Nasou, Elsiesrivier, 599 pp.

14. Terblanche, H.J. (1974). Afrikaans as vak-en tegniese taal. In Afrikaans, ons pêrel van groot waarde, Federasie van Afrikaanse Kultuurvereniginge, Johannesburg, pp. 186- 197.

15. Malherbe, D.F. du T. (1918). Engels-Afrikaanse Skeikundige Terminologie. Bloemfontein. (Aangehaal in F.J. Snijman 1974, verwysing 22 hieronder.)

16. Odendaal, F.F. et al. (1981). Verklarende handwoordeboek van die Afrikaanse taal. Perskor, Johannesburg, 1378 pp.

17. Naudé, M. (1974). Afrikaans en die wetenskap. In Afrikaans, ons pêrel van groot waarde, Federasie van Afrikaanse Kultuurvereniginge, Johannesburg, pp. 174-185.

18. Posthumus, M.J. (1956/7). Drie opstelle oor termkunde. Tydskr. Volkskunde Volkstaal, 12 (84), 1-6; 13(1), 18-23; 13(3), 13-20. (Aangehaal in J.C. Steyn, 1980, verwysing 19 hieronder.)

19. Steyn, J.C. (1980). Tuiste in Eie Taal. Die behoud en bestaan van Afrikaans. Tafelberg, Kaapstad, 523 pp.

20. Hermans, W.F. (1979). Houten leeuwen en leeuwen van goud. De Bezige Bij, Amsterdam. (Aangehaal in J.C. Steyn, 1980, verwysing 19 hierbo).

21. Woordeboek van die Afrikaanse taal. Dele I tot VI, Die Staatsdrukker, Pretoria.

22. Snijman, F.J. (1974). Verskeidenheid in ons taal. In Afrikaans, ons pêrel van groot waarde, Federasie van Afrikaanse Kultuurvereniginge, Johannesburg, pp. 66-80. 